\title{
Secular trends in opioid prescribing in the USA
}

\section{Edmund J Pezalla' \\ David Rosen ${ }^{2}$ \\ Jennifer G Erensen ${ }^{2}$ \\ J David Haddox ${ }^{2,3}$ \\ Tracy J Mayne ${ }^{2}$}

'Bioconsult, LLC, Wethersfield, 2Purdue Pharma L.P., Stamford, CT, ${ }^{3}$ Public Health and Community Medicine, Tufts University School of Medicine, Boston, MA, USA

\section{Video abstract}

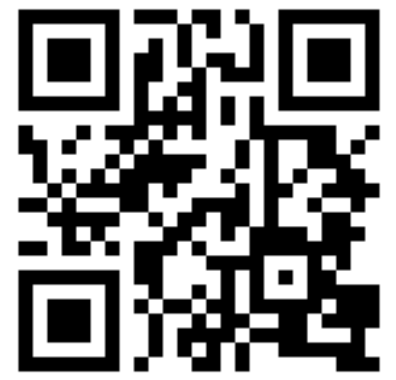

Point your SmartPhone at the code above. If you have a QR code reader the video abstract will appear. Or use: http://youtu.be/svVxELL_Vik
Correspondence: Tracy J Mayne Medical Affairs Strategic Research, Purdue Pharma L.P., 20I, Tresser Blvd, Stamford, CT 0690I, USA

Tel +l 2035887143

Email Tracy.Mayne@pharma.com
This article was published in the following Dove Press journal:

Journal of Pain Research

14 February 2017

Number of times this article has been viewed

Abstract: Opioid abuse and misuse in the USA is a public health crisis. The use of prescription opioid analgesics increased substantially from 2002 through 2010, then plateaued and began to decrease in 2011. This study examined prescriptions of branded and generic immediate- and extended-release opioid analgesics from 1992 to 2016. This was juxtaposed against state and federal policies designed to decrease overutilization and abuse, as well as the launch of new opioid products, including opioids with abuse-deterrent properties (OADPs). The data indicate that these health policies, including the utilization and reimbursement of OADPs, have coincided with decreased opioid utilization. The hypothesis that OADPs will paradoxically increase opioid prescribing is not supported.

Keywords: OADP, prescription, utilization trends, legislation, opioids

\section{Introduction}

Abuse and misuse of opioid analgesics is a public health crisis in the USA. ${ }^{1}$ Over 10 million people aged 12 years and older used opioid analgesics nonmedically in 2014, with almost 2 million meeting diagnostic criteria for opioid use disorder. ${ }^{2}$ Overdose fatalities involving opioid analgesics have increased steadily over the last 15 years. ${ }^{1}$

As a result of these trends, numerous policies have been implemented to curb abuse, misuse, and diversion of prescription opioids, and to improve medical practice around opioid use (Table 1).

There has been a concerted effort to decrease the desirability of prescription opioids to abusers by deterring easy physical manipulation and extraction of their active ingredients. In 2015, the US Food and Drug Administration (FDA) finalized a process for approving opioids with abuse-deterrent properties (OADPs). ${ }^{3}$ To date, seven opioids have met stringent FDA criteria to carry labeling claims that the product is "expected to result in a meaningful reduction" in its abuse. ${ }^{4}$ All OADPs approved to date have been extended-release opioids.

Concerns have been raised that policy efforts to contain and reverse opioid abuse and related deaths may have unintended consequences. For example, some insurers have indicated that abuse-deterrent opioids may give physicians a false sense of security and lead to an increase in opioid prescribing. ${ }^{5}$ Insurers also have concerns that legislative policies mandating coverage of OADPs will shift the market from generic to branded opioid medications, at significant incremental cost to plans and patients. 
The goal of this study is to examine prescribing trends for opioid analgesics against the backdrop of public policies aimed at reducing opioid overutilization and abuse, as well as the introduction and increased use of OADPs.

\section{Method: prescription opioid analgesic market review}

This analysis examined US opioid prescriptions from January 1, 1992, to August 31, 2016, in IMS Health National Prescription Audit. This database is the industry standard source for dispensed prescriptions from retail pharmacies in all 50 states. The data set includes $86 \%$ of prescriptions captured from a sample of 46,500 pharmacies, stratified by geographic location of retail, mail service, and longterm care. It then uses a proprietary algorithm to project a nationally representative sample. The analysis included all oral, transdermal, immediate-release, extended-release, single-entity, and combination opioid products. Prescription trends were examined to evaluate changes in opioid market composition - potential effects of new market entrants and policy implementations.

\section{Results}

The total number of dispensed opioid analgesic prescriptions grew steadily from 1992 until 2010 (Figure 1, Table S1). In August 2010, a new formulation of OxyContin ${ }^{\circledR}$ (oxycodone hydrochloride) extended-release tablets was introduced. In April 2013, it became the first opioid analgesic to receive labeled description of abuse-deterrent properties, and the New Drug Application (NDA) for the original formulation was withdrawn. Subsequent new opioid launches included three additional extended-release formulations with FDAapproved abuse-deterrent properties: Hysingla ${ }^{\circledR}$ ER (hydrocodone extended-release tablets), Embeda ${ }^{\circledR}$ (morphine sulfate and naltrexone hydrochloride extended-release capsules), and Xtampza ${ }^{\circledR}$ ER (oxycodone extended-release capsules). ${ }^{6}$

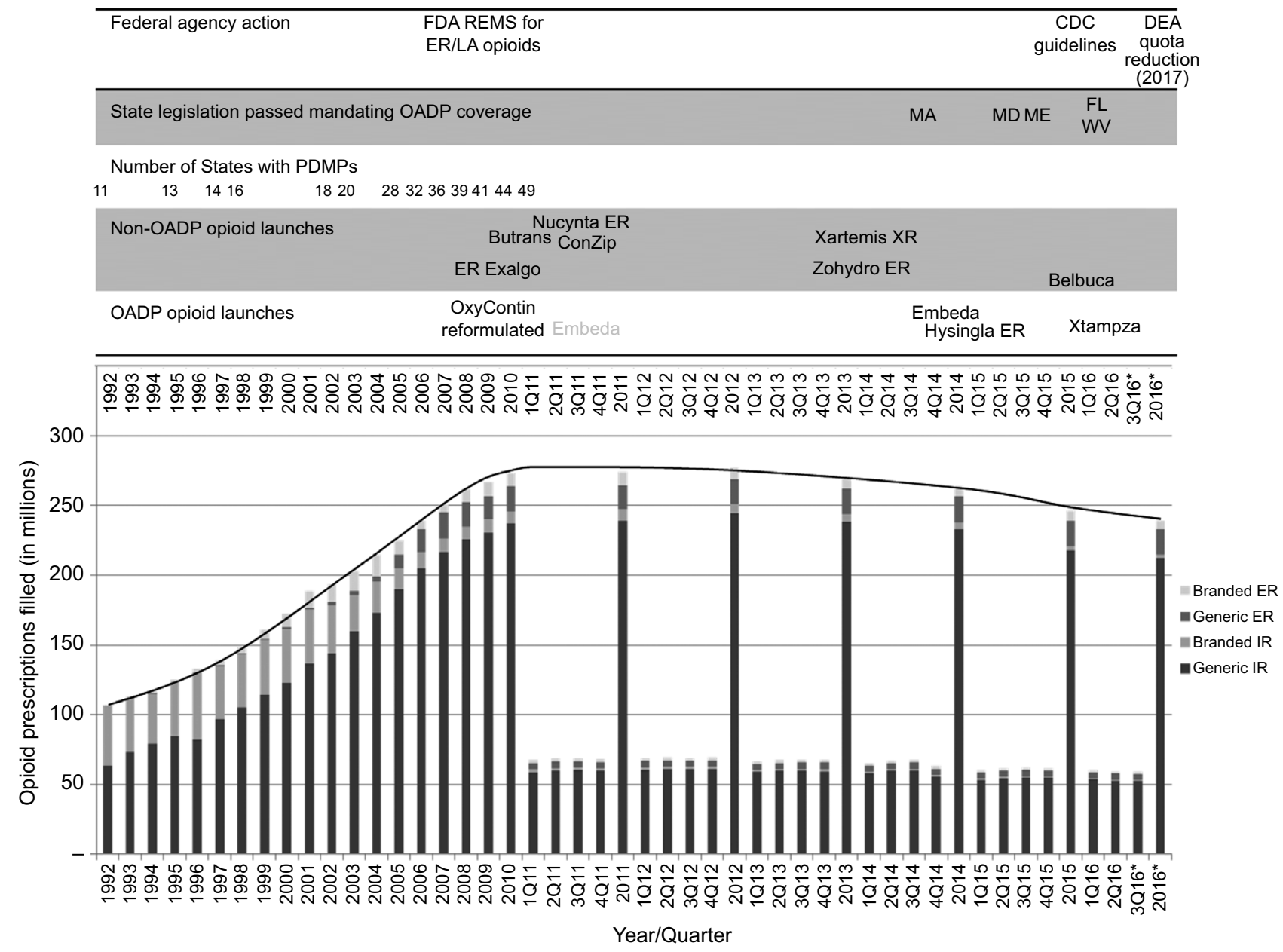

Figure I Opioid prescriptions dispensed by year with opioid launches, coverage legislation, PDMP adoption and major federal agency actions. Note: *Estimated. Data reported quarterly from first quarter $201 \mathrm{I}$.

Abbreviations: CDC, Centers for Disease Control and Prevention; DEA, Drug Enforcement Administration; ER, extended release; ER/LA, extended-release and longacting; FDA, US Food and Drug Administration; FL, Florida; IR, immediate release; MA, Massachusetts; MD, Maryland; ME, Maine; OADP, opioids with abuse-deterrent properties; PDMPs, prescription drug monitoring programs; REM, risk evaluation and mitigation strategy; WV, West Virginia; XR, Extended-Release. 
During the timeframe that these new OADPs were introduced into the marketplace, an increasing number of policies aimed at reducing opioid overutilization and abuse also came into effect (Table 1 and Figure 1). These included state legislation defining Pain Clinics and Pain Physicians; FDA Risk Evaluation and Mitigation Strategy (REMS) for the ExtendedRelease, and Long-Acting (ER/LA) Opioid Analgesics; opioidrelated prescribing guidelines including those released by the Centers for Disease Control and Prevention; Prescription Drug Monitoring Programs (PDMP); and most recently, state legislation mandating insurance coverage of OADPs.

Together, these forces initiated a market contraction in 2011 that is continuing through 2016.

- The total number of dispensed opioid prescriptions declined by $2.2 \%$ in $2014,6.8 \%$ in 2015 , and are projected to decrease by $2.9 \%$ by year-end 2016 .

- Prescriptions dispensed for branded opioid analgesics are a decreasing proportion of the opioid market constituting a $4.8 \%$ prescription share in $2014,4.1 \%$ share in 2015 , and a projected $3.7 \%$ share in 2016.

- Since 2010, the number of dosing units per extendedrelease opioid prescription dispensed has decreased $20 \%$, from 67 to 54 .

Table I Selected initiatives at the state and federal levels ${ }^{14-18}$

Level Initiatives

State

Prescription Drug Monitoring Programs (PDMPs)

Prescribing Guidelines, some with morphine milligram equivalent (MME) dose limits

Pain Management CME Requirements

State Pain Clinic/Pain Physician Requirements ("Pill Mill" Laws)

"Good Samaritan" Laws - immunity to summon medical

assistance for overdose

Increased availability of naloxone for overdose reversal

Federal

Office of National Drug Control Policy - 20I I National Drug

Control Strategy Supplement

FDA Risk Evaluation and Mitigation Strategies (ER/LA opioids, TIRF)

CMS Overutilization Monitoring System for opioids

CDC Guideline for primary care providers on Prescribing

Opioids for Chronic Pain

FDA Opioid Action Plan

NIH Pathways to Prevention

National Pain Strategy

US Surgeon General - Turn-the-tide initiative

DEA reduction in opioid controlled substances quotas (to be implemented in 2017)

Abbreviations: CDC, Centers for Disease Control and Prevention; CME, continuing medical information; CMS, Centers for Medicare \& Medicaid Services; DEA, Drug Enforcement Administration; ER/LA, extended-release and long-acting, FDA, US Food and Drug Administration; MME, morphine milligram equivalent; NIH, National Institutes of Health; PDMPs, prescription drug monitoring programs; TIRF, Transmucosal Immediate Release Fentanyl.
- Since 2010, the total number of kilograms of opioid prescriptions dispensed in the USA has decreased 16\%, from 271,000 to $227,000 \mathrm{~kg}$.

- Since 2010, prescriptions dispensed for extended-release opioids of $>90$ morphine milligram equivalents (MME) in the USA have decreased $34 \%$, from 5.3 million to 3.5 million.

In addition, without a formal determination by Drug Enforcement Administration (DEA) of aggregate and company active pharmaceutical ingredients (API) quotas, there can be no sudden market expansion of opioids or OADPs. ${ }^{7}$ Recent DEA action, affecting morphine, hydromorphone, oxycodone, hydrocodone, and fentanyl, will reinforce the current reduction in utilization and preclude expansion of the US prescription opioid analgesic market. ${ }^{7}$

\section{Conclusion}

The US prescription opioid analgesic market has been consistently contracting since 2011 and continues to shrink in response to changes in public policy and medical practice, notwithstanding the increasing availability of products designed to deter abuse. Fewer patients are being prescribed opioids, the amounts prescribed are less, the daily doses are less, and there is a national emphasis on non-opioid treatment alternatives. These data are consistent with other research on the effectiveness of public policy and the introduction of OADPs. ${ }^{4,8-12}$

While these data are encouraging, there are other factors that continue to fuel the opioid epidemic in the USA. There has been an increase in the availability of cheap and pure heroin, and an influx of non-pharmaceutical, illicitly-manufactured fentanyl. ${ }^{13}$ While the increase in opioid deaths observed from 2002 to 2011 was largely driven by the misuse and abuse of prescription opioids, data from 2012 to 2014 indicate that deaths involving prescription opioids appear to have stabilized, while deaths involving heroin and illicit fentanyl were driving increases in opioid-involved mortality. ${ }^{1}$ While policies and actions intended to curb prescription opioid abuse are having the desired effect, continued action will be necessary to address the broader problem as the opioid crisis evolves.

In conclusion, public health policies and actions have resulted in decreased utilization of prescription opioids. Neither the launch of OADPs nor policies mandating their coverage has grown the opioid market: both branded and generic medications, immediate-release and extendedrelease, are decreasing. Taken together, these findings indicate that public health policies and the introduction of OADPs are having the intended effect of reducing the inappropriate utilization of opioids, resulting in a contraction in the overall 
opioid market, without evidence of paradoxical increases in opioid prescribing, nor increases in market share for branded extended-release opioids.

\section{Disclosure}

EJP is a consultant. DR, JGE, JDH, and TJM are employees of Purdue Pharma L.P. The authors report no other conflicts of interest in this work.

\section{References}

1. Rudd RA, Aleshire N, Zibbell JE, Gladden RM. Increases in drug and opioid overdose deaths — United States, 2000-2014. MMWR Morb Mortal Wkly Rep. 2016;64(50-51):1378-1382.

2. Center for Behavioral Health Statistics and Quality. 2014 National Survey on Drug Use and Health: Detailed Tables. Substance Abuse and Mental Health Services Administration; 2015. Available from: http://www.samhsa.gov/data/sites/default/files/NSDUH-DetTabs2014/ NSDUH-DetTabs2014.pdf. Accessed October 28, 2016.

3. FDA guidance on abuse-deterrent opioids - evaluation and labeling. Available from: http:/www.fda.gov/RegulatoryInformation/Guidances/ default.htm. Accessed October 29, 2016.

4. Warner M, Hedegaard H, Chen LH. Trends in Drug-Poisoning Deaths Involving Opioid Analgesics and Heroin: United States, 1999-2012;2014. Available from: https://www.cdc.gov/nchs/data/hestat/drug_poisoning/drug_poisoning_deaths_1999-2012.pdf. Accessed October 29, 2016.

5. Opioid abuse task force. Assembly Committee on Health, AB1977 (Wood)-Amended April 13; 2016. Available from: www.legtrack.com/ cache/285312.doc. Accessed November 2, 2016.

6. FDA Facts Abuse-Deterrent Opioid Medications. Available from: http:// www.fda.gov/NewsEvents/Newsroom/FactSheets/ucm514939.htm. Accessed November 2, 2016.
7. DEA Reduces amount of opioid controlled substances to be manufactured in 2017. Available from: https:/www.dea.gov/divisions/hq/2016/ hq100416.shtml. Accessed October 29, 2016.

8. Levy B, Paulozzi L, Mack KA, Jones CM. Trends in opioid analgesicprescribing rates by specialty, U.S., 2007-2012. Am J Prev Med. 2015;49(3):409-413.

9. Dart RC, Surratt HL, Cicero TJ, et al. Trends in opioid analgesic abuse and mortality in the United States. N Engl J Med. 2015;372(3):241-248.

10. Cicero TJ, Ellis MS. Abuse-deterrent formulations and the prescription opioid abuse epidemic in the United States: lessons learned from OxyContin. JAMA Psychiat. 2015;72(5):424-429.

11. Johnson H, Paulozzi L, Porucznik C, Mack K, Herter B. Decline in drug overdose deaths after state policy changes - Florida, 2010-2012. MMWR Morb Mortal Wkly Rep. 2014;63(26):569-574.

12. Compton WM, Jones CM, Baldwin GT. Relationship between nonmedical prescription-opioid use and heroin use. $N$ Engl J Med. 2016;374(2):154-163.

13. Centers for Disease Control and Prevention. Influx of Fentanyl-Laced Counterfeit Pills and Toxic Fentanyl-Related Compounds Further Increases Risk of Fentanyl-Related Overdose and Fatalities. HAN Health Advisory; 2016. Available from: http://health.mo.gov/emergencies/ert/ alertsadvisories/pdf/cdc-update82616.pdf. Accessed October 29, 2016.

14. Smith PC1, Schmidt SM, Allensworth-Davies D, Saitz R. A singlequestion screening test for drug use in primary care. Arch Intern Med. 2010;170(13):1155-1160.

15. Haffajee RL, Jena AB, Weiner SG. Mandatory use of prescription drug monitoring programs. JAMA. 2015;313(9):891-892.

16. NIH Pathways to Prevention Workshop: The Role of Opioids in the Treatment of Chronic Pain; 2014. Bethesda, MD. Available from: https:// prevention.nih.gov/docs/programs/p2p/OpioidPainTreatmnt_ProgramBook.pdf. Accessed November 2, 2016.

17. Volkow ND, McLellan AT. Opioid abuse in chronic pain - misconceptions and mitigation strategies. NEngl JMed. 2016;374(13):1253-1263.

18. State Naloxone and Good Samaritan Legislation, December, 2015. Available from: https://www.whitehouse.gov/sites/default/files/ondcp/ Blog/naloxonecirclechart_january2016.pdf. Accessed October 16, 2016. 


\section{Supplementary material}

Table SI Trends of opioid prescription data by year

\begin{tabular}{|c|c|c|c|c|c|c|c|c|c|c|c|c|c|c|c|c|}
\hline TRx (MM) & 1992 & 1993 & 1994 & 1995 & 1996 & 1997 & 1998 & 1999 & 2000 & 2001 & 2002 & 2003 & 2004 & 2005 & 2006 & 2007 \\
\hline Generic IR & 63.3 & 73.4 & 79.1 & 84.8 & 82.3 & 96.7 & 105.4 & 114.5 & 122.8 & 136.6 & | 44.1 & 159.6 & I73.I & 189.8 & 205.0 & 216.7 \\
\hline Branded IR & 42.9 & 38.3 & 36.1 & 38.4 & 48.3 & 38.3 & 38.2 & 38.9 & 38.7 & 38.7 & 34.6 & 26.3 & 22.4 & 15.1 & 11.4 & 9.4 \\
\hline Generic ER & 0.1 & 0.1 & 0.2 & 0.3 & 0.3 & 0.4 & 0.5 & 0.8 & 1.2 & 1.6 & 2.3 & 2.8 & 3.6 & 10.2 & 16.5 & 19.0 \\
\hline Branded ER & 1.0 & 1.3 & 1.5 & 1.9 & 2.5 & 3.4 & 4.7 & 6.6 & 9.7 & 11.8 & 12.9 & 14.7 & 15.5 & 10.2 & 6.1 & 5.7 \\
\hline All Opioids & 107.26 & 113.12 & 116.95 & 125.38 & 133.38 & 138.90 & 148.93 & 160.90 & 172.46 & 188.62 & 193.89 & 203.33 & 214.57 & 225.27 & 238.96 & 250.78 \\
\hline TRx (MM) & 2008 & 2009 & 2010 & IQII & 2QII & 3QII & 4QII & 2011 & IQI2 & 2Q12 & $3 Q 12$ & $4 Q 12$ & 2012 & IQI3 & $2 Q 13$ & $3 Q 13$ \\
\hline Generic IR & 226.0 & 230.9 & 237.4 & 58.8 & 59.7 & 60.4 & 59.9 & 238.8 & 60.8 & 61.1 & 61.0 & 61.4 & 244.3 & 59.3 & 59.8 & 60.0 \\
\hline Branded IR & 8.7 & 9.2 & 8.5 & 2.2 & 2.2 & 2.0 & 1.9 & 8.4 & 1.8 & 1.8 & 1.7 & 1.4 & 6.7 & 0.9 & 1.3 & 1.3 \\
\hline Generic ER & 17.7 & 16.6 & 17.9 & 4.3 & 4.4 & 4.3 & 4.4 & 17.4 & 4.4 & 4.5 & 4.5 & 4.5 & 17.9 & 4.4 & 4.5 & 4.6 \\
\hline Branded ER & 9.5 & 10.3 & 9.4 & 2.4 & 2.4 & 2.4 & 2.4 & 9.5 & 2.1 & 2.1 & 2.1 & 2.1 & 8.4 & 2.0 & 2.0 & 2.0 \\
\hline All Opioids & 261.95 & 266.99 & 273.29 & & & & & 274.14 & & & & & 277.29 & & & \\
\hline TRx (MM) & $4 Q 13$ & 2013 & IQI4 & 2Q14 & $3 Q 14$ & 4Q14 & 2014 & IQI5 & $2 Q 15$ & $3 Q 15$ & 4QI5 & 2015 & IQ16 & $2 Q 16$ & 3Q16* & 2016* \\
\hline Generic IR & 59.6 & 238.7 & 57.8 & 59.6 & 59.9 & 55.6 & 232.9 & 53.3 & 54.7 & 55.1 & 54.8 & 217.9 & 53.6 & 52.7 & 52.7 & 212.2 \\
\hline Branded IR & 1.7 & 5.2 & 1.4 & 1.4 & 1.3 & 1.1 & 5.2 & 1.0 & 0.9 & 0.7 & 0.7 & 3.2 & 0.7 & 0.6 & 0.6 & 2.6 \\
\hline Generic ER & 4.6 & 18.1 & 4.5 & 4.6 & 4.7 & 4.7 & 18.3 & 4.5 & 4.6 & 4.6 & 4.6 & 18.2 & 4.5 & 4.5 & 4.5 & 17.9 \\
\hline Branded ER & 2.0 & 8.0 & 1.9 & 1.9 & 1.9 & 1.9 & 7.6 & 1.7 & 1.7 & 1.7 & 1.7 & 6.9 & 1.6 & 1.5 & 1.5 & 6.2 \\
\hline All Opioids & & 270.06 & & & & & 264.07 & & & & & 246.22 & & & & 238.98 \\
\hline
\end{tabular}

Note: *Estimated.

Abbreviations: ER, extended release; IR, immediate release; TRx, total prescriptions; MM, million.

The Journal of Pain Research is an international, peer reviewed, open access, online journal that welcomes laboratory and clinical findings in the fields of pain research and the prevention and management of pain. Original research, reviews, symposium reports, hypothesis formation and commentaries are all considered for publication.
The manuscript management system is completely online and includes a very quick and fair peer-review system, which is all easy to use. Visit http://www.dovepress.com/testimonials.php to read real quotes from published authors. 